\title{
The Co-archiving Toolbox - Designing conditions for diversity in public archives
}

\author{
NILSSON Elisabet M.* and OTTSEN HANSEN Sofie Marie \\ Malmö University \\ * Corresponding author e-mail: elisabet.nilsson@mau.se \\ doi: 10.21606/dma.2018.353
}

\begin{abstract}
This paper reports the development of a method for increasing the diversity in public archives, referred to as the Co-archiving Toolbox and developed in collaboration with three museums. Museum professionals and refugees were invited to co-design workshops to explore and prototype alternative ways to document and archive refugee stories - told in their own voices and through their own perspectives. Besides elaborating on alternative, and more inclusive archiving practices, the project also explored how co-design approaches and prototyping can become a resource in rethinking the role of archivists and museum professionals who are interested in coarchival facilitation. The co-archiving toolbox currently includes seven co-archiving practices designed to be applied at temporary refugee housing but could potentially also be used in other contexts. The project may serve as an example of how design interventions can contribute to developing existing archival practices by encouraging archivists and museum professionals to assume a collaborative approach.
\end{abstract}

co-archiving; co-design; refugees; museum professionals

\section{Introduction}

Living Archives is an interdisciplinary research project exploring archives and archiving practices in a digitized society from a range of perspectives. The purpose of the project "is to research, analyze and prototype how archives for public cultural heritage can become a significant social resource, creating social change, cultural awareness and collective collaboration pointing towards a shared future of a society" (livingarchives.mah.se, accessed on 2018-03-06).

One of the research themes of the project is co-archiving, which aims to explore and develop collaborative (co-)archiving practices involving underrepresented voices in generating archival material for the public archives. The underlying assumption is that this inclusive archiving approach opens up the archiving process by inviting more people to contribute to the public archives, which would create conditions for diversity and result in more representative records of human existence (Dunbar, 2006; Warren, 2016).

The starting point for the co-archiving research theme began with a quotation by Derrida (1995, p. 4): "There is no political power without control of the archive, if not memory. Effective democratization can always be measured by this essential criterion: the participation in and access to the archive, its constitution, and its interpretation." Until now, a series of design interventions have been conducted where various co-archiving practices have been prototyped and reported on 
(see e.g. Nilsson, 2015, 2016; Nilsson \& Barton, 2016; Nilsson \& Ottsen Hansen, 2017). The first phase of the project had a focus on marginalized urban communities and neighbourhoods and resulted in six co-archiving practices designed to invite communities to collect, store and share their memories and cultural heritages: Eat a Memory, Plant Your History, The Memory Game, Soil Memories, Mosaic of Malmö, and Designing an Archiving Practice Using Comedy (Nilsson, 2015, 2016).

In the second phase of the project, our focus shifted towards refugees seeking asylum in Sweden (Nilsson \& Ottsen Hansen, 2016; Nilsson \& Barton, 2016). The shift was a reaction to the current world situation, where many people have been forced to leave their homes in war zones and seek protection in other countries. In 2015, nearly 163,000 persons sought asylum in Sweden (Swedish Migration Agency, 2015). A collaboration was initiated with the Refugee Documentation Project run by the three largest museums in southern Sweden aimed at documenting the emergent refugee situation in Sweden (Nikolić, 2016). Building on their experiences as well as on learning outcomes from previous design interventions within the co-archiving research theme, the Co-archiving Refugee Documentation Project was established. The aim is to design co-archiving practices for inviting refugees to share and document their experiences from their point of view and not through the lens of the "other", that is, those who gather the documentation, interview, filter, select and archive. The target group for these co-archiving practices is not only the unheard, in this case, refugees, but also the archivists and museum professionals who are interested in assuming a co-archiving facilitation approach by engaging the subjects (the "archived") in the shaping of archives (Nilsson, 2016).

This paper reports the development of a method for increasing the participation in archives, referred to as the Co-archiving Toolbox. It includes a set of archiving practices designed to be applied at temporary refugee housing but could potentially also be used in other contexts. The main focus of this paper is to present the toolbox, the co-archiving practices it houses and how it can be used in the field. The specific design activities conducted in the four workshops are briefly introduced and will be more thoroughly presented and reflected upon in future writings.

\subsection{Design as a Catalyst for Change}

In regard to the conference theme, Designing social innovation in cultural diversity and sensitivity, we believe that our project can serve as example of how design interventions can contribute to developing and changing existing archival practices by encouraging archivists and museum professionals to assume a collaborative approach. This is not to say that these professions are not working in an inclusive way to ensure diversity in our archives because many are, but rather, in our work, we wish to explore what parallels can be drawn between the practices of co-designers and archivists/museum professionals and how these two domains can work together to reconfigure archiving practices, prototype alternatives and address the complex challenges of democratizing access to and participation in archives. As mentioned, to have access to and be able to participate in the archives reflects political power (Derrida, 1995). In a democracy, we ought to ensure that all groups are invited to contribute to the archives and constantly re-think and develop new approaches, methods and practices for achieving this.

\section{Background}

\subsection{Archiving for diversity}

As stated in previous work (see Dunbar, 2006; Warren, 2016; Johnstone, 2001 in Nilsson, 2016; Nilsson \& Hansen, 2017), an ongoing debate in the field of archival studies is addressing the underrepresentation of marginalized communities in archives and how we can possibly provide the future with a more representative record of human experience. As argued, instead of continuing to document the "well-documented", archivists and museum professionals ought to be encouraged to assume a more inclusive approach and open up the archiving process to ensure increased diversity in our archives. However, this discussion is nothing new. In the 1970s, archivists were encouraged to 
become "activist archivists" striving to represent all people and communities by going from biased archival records to more representative records of human experience (Johnstone, 2001).

As emphasized by Manoff (2004), "The writing of history always requires the intervention of a human interpreter" (ibid, p. 16). We ought to recognize that the historical record is not an objective representation of the past but rather a curated selection of objects that have been preserved for various reasons. The silence and the absence of material and documents in the archives also speak to us.

\subsection{The Refugee Documentation Project}

The three largest museums in southern Sweden are currently running the Refugee Documentation Project (Nikolić, 2016), through which they have documented and now share a wide collection of refugees' stories and experiences. They have also collected testimonies from the many volunteers and activists who participated in welcoming the people arriving to the city of Malmö in the autumn of 2015. Previously, the documenting and archiving process followed well-established practices from the field of ethnology (e.g. participatory observations, interviews, video and audio recordings, and questionnaires). Their documentation processes resulted not only in much archival material but also in new research questions dealing with methodological challenges regarding matters of inclusion and representation when documenting crisis situations (Nikolić, 2016). In what ways can we develop approaches, methods and practices for museological ethnology characterized by an inclusive approach inviting people to directly share their experiences?

\subsection{The Co-archiving Refugee Documentation Project}

The Co-archiving Refugee Documentation Project is based on the questions that arose in the museums' work with the Refugee Documentation Project in addition to the outcome of the previous co-archiving design interventions. The aim of the project is to set up a co-design process which invites both refugees and museum professionals to take part in developing new ways to document and archive refugee stories - told in their own voices and through their own perspectives. As well as elaborating on new practices for museological ethnology, we also explore how prototyping and codesign approaches can become a resource in re-thinking the role of archivists and museum professionals who are interested in assuming a co-archival facilitation approach.

In addition to the project introduced above, two more design projects have been conducted as a part of the overall project run by Master's students in Interaction Design. The first project was as part of a course in collaborative media and resulted in a collection of concept ideas: StoryMap, Conversation Archiving, and StoryBox, which are co-archiving practices that allow communities to capture their experiences from their own perspectives (Living Archives, 2017). The second design project was a Master's thesis project where a collaborative self-archiving system for vulnerable groups was co-designed and explored (Dimitrova, 2017). In addition to the Co-archiving Toolbox concept, both projects served as inspiration and have contributed to the outcome of the design process described in the following section.

\section{Research approach and methods}

The research approach taken is that of design research, which has its roots in action research (Agyris et al. 1985), which, since the beginning, has been about creating alternative futures and supporting democratic changes by involving the users in collaborative (co-)design processes. An emphasis is placed on the political motivation and the ethical standpoint that those affected by design ought to have a say in the design process. The focus has been on the overall belief that inviting the user "into the design of invisible mediating structures around them" (Light \& Akama, 2014, p. 153) will result in more sustainable solutions and a more democratic future. Thus, the direct involvement of the users is one of the central principles of participatory design and co-design approaches. Instead of designing for the users, the designers and researchers co-design with the users in a process of joint decision-making, mutual learning and co-creation (Simonsen \& Robertson, 2013). 
Accordingly, our research process was guided by the principles and methods from the field of participatory design (Simonsen \& Robertson, 2013). The workshops conducted as part of this project were designed to support collaborative inquiry, joint explorations and mutual learning between the participants. This was achieved through the use of various generative tools (physical things that people use) and techniques (the ways in which these tools are used) (Sanders \& Stappers, 2012). The concept of generative tools refers to "the creation of shared design language that designers/researchers and other stakeholders use to communicate visually and directly with each other" (ibid., p. 20).

By applying a selection of generative tools and techniques, the participants were able to articulate and translate their ideas, needs and interests into tangible articulations: photos, texts, sketches, prototypes. Such design practices can be viewed as a translational process for expressing meaning in different languages, materializing different possibilities, and providing a form of connection between the participants (Callon \& Latour, 1981). The framing and re-framing of the problems or challenges are not carried out solely by one participant but rather in a reflective conversation between the participants, where doing and thinking are complementary (Schön, 1987).

\subsection{Tools and techniques applied}

Various generative design tools and techniques were applied at the workshops. During the week leading up the first workshop, we invited the participants to be part of a sensitizing activity consisting of a small documentation exercise. The participants were asked to document four small fragments of their everyday life by answering four simple questions sent via text message. The belief is that engaging the participants with the topic in advance will cause them to become more sensitive to their awakened memories and associations and thus come more prepared to the workshop (Sanders \& Stappers, 2012). The collected material was used at the first workshop to set up productive communication between the participants and level the field between the two groups. The material was applied in a mapping activity, which was about making sense of the fragments of information they all had been part of generating.

In addition to the sensitizing exercise, the participants were asked to bring a personal item that they, for whatever reason, would like to keep for the future (e.g. an object, a document, a photo, a sound, a scent, a book). The purpose of the activity was to prompt the participants to connect to, express and articulate what is meaningful for them to preserve and archive. The activity was aimed at supporting them as they access and articulate their underlying values. The outcome also served as a basis for, and provided input to, the subsequent workshop activity, which was about ideating solutions and future practices for how to capture and archive these categories of memories. Materials and the surrounding physical environment matter in creative and collaborative processes (Sanders \& Stappers, 2012); thus, various kinds of creative materials were provided - paper, pens, scrap material, photos, Lego. A trigger set (ibid.) was also developed and provided to help the participants express their ideas or to trigger ideas by providing concrete inspiration.

Building on the outcome of first workshop and after analysing the collected data, seven early concept ideas were developed. During the second and third workshops, these ideas were introduced to the participants for them to react upon, evaluate and re-design. They were presented on posters and were open for adjustments and further sketching (with various sketch materials provided). The ideas were introduced then followed by an evaluation exercise conducted individually and followed by a common discussion about potentials and problems. This setup allowed the participants to oscillate between individual reflection and collective creativity. Through this process, the ideas were either rejected or re-designed, and new concept ideas also emerged.

We compiled the outcome of the three workshops, and the concept ideas were materialized in a cardboard prototype, which was presented at the fourth workshop. This prototype was to be understood as an articulation of potential design solutions (Lawson, 2005) open to further iterations and as a foundation for discussion. In addition to trying out and reconfiguring the prototype, the 
participants were also asked to develop a first draft of a praxis around using it in the field. They were given a set of tools to support their process - a timeline and various scrap materials - and were instructed to identify important matters to consider before, during, and after using the concept in the field.

\section{The design process}

\subsection{Research setting}

Four workshops were organized which invited museum professionals and refugees to take part in a co-designing process. Workshops 1-3 involved four members of the Refugee Documentation Project (two females and two males) and four refugees (all female) who originate from Eritrea, Afghanistan, Albania and Kosovo and live with their families in temporary refugee housing in southern Sweden. The refugees had arrived to Sweden nearly two years ago to seek asylum and are still waiting to hear from the Swedish Migration Agency. The fourth workshop involved eight museum professionals. Seven of them were new to the project and had not taken part in the previous design activities. One was involved with the Refugee Documentation Project group in addition to initiating the workshop, where she invited colleagues to join from the museum where she works.

The workshops 1, 2, and 4 were held in the facilities of the university, and workshop 3 was held at the temporary refugee housing. On average, the workshops were 3 hours long and were conducted over the course of $3 \frac{1}{2}$ months. In addition to being photographed, the sessions were also audio- and videotaped.

\subsubsection{Ethical considerations}

Our work follows the ethical standards as formulated in Codex rules and guidelines for research in Humanities and Social sciences (The Swedish Research Council, n.d.). The participants were informed about the research projects before participating and were freely willing to participate. In connection with the workshops, the participants were orally informed about their rights, that their contributions were to be treated anonymously, and that the gathered material (sketches, video, audio, photographs) would be used for research purposes only. The participants in workshops 1-3 were asked to sign a Letter of Consent. In workshop 4, the participants gave oral consent to take part in the project.

\subsection{Four workshops}

\subsubsection{Workshop 1}

The focus of the first workshop was Envisioning the Archive where the design activities focused on enabling the participants to access and share their personal values and identifying relevant themes they found important in regard to sharing their stories and communicating who they are. Four museum professionals and four refugees participated in the workshop.

The design activities also focused on creating a common ground for the two groups of participants. At the workshop, we gained insight into how different objects could hold different meaning in the personal archive. This resulted in six design principles - insights that more concretely related to how to actually design for this specific context and purpose. Three opportunity statements were formulated providing focused challenges to work with:

- How might we capture and preserve the refugees' experience of waiting?

- How might we capture and preserve the refugees' dreams for a possible future?

- How might we capture and preserve the individual behind the number?

Based on these insights, seven proposals for co-archiving practices were developed. 

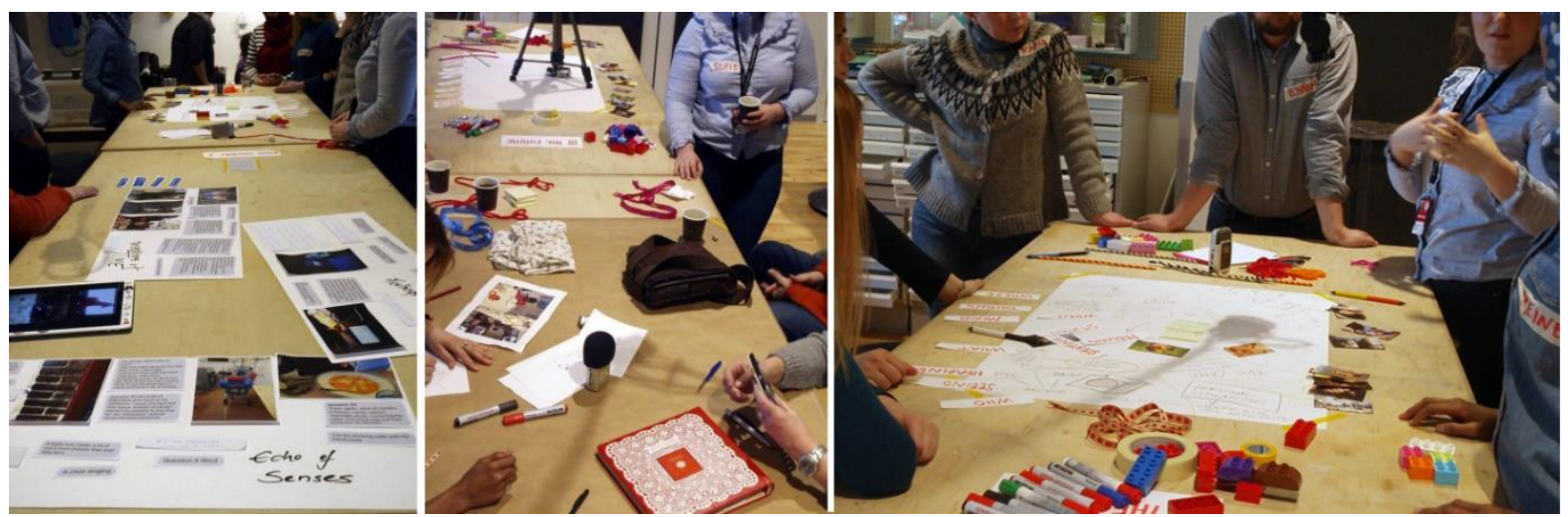

Figure 1 Design activities at the first workshop.

\subsubsection{Workshop 2}

The second workshop focused on Doing the Archive and aimed at facilitating the evaluation and redesign of concrete co-archiving practices. The seven co-archiving practices building on the outcome of workshop 1 were presented, and four museum professionals participated.

After having presented the concepts, we asked the participants to individually evaluate them by placing stickers on the concept idea description posters (i.e. pink $=$ idea with potential, blue $=$ bad idea). This was followed by a joint discussion about the potentials and problems with the concepts, whereby the ideas were either rejected or else re-designed. In addition to the seven presented practices, one additional concept idea was generated as a result of the discussion.
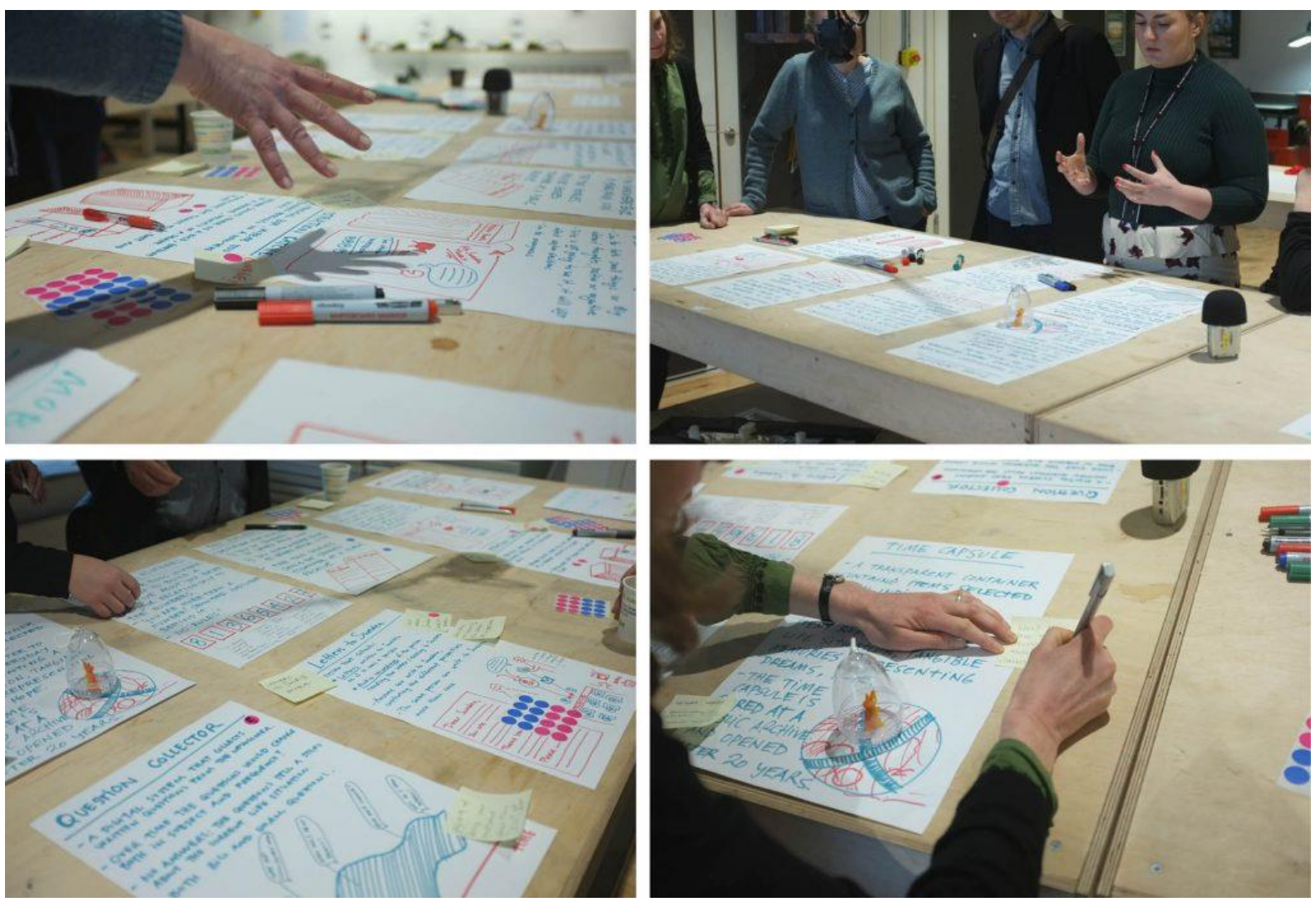

Figure 2 Concept ideas evaluated by the museum professionals at the second workshop.

\subsubsection{Workshop 3}

The third workshop followed the same setup as workshop 2. Eight co-archiving practices were presented, evaluated and re-designed. Three refugees participated in the workshop. 
When comparing the results of workshops 2 and 3, it became clear that the museum practitioners and the refugees did not share the same viewpoint. The practitioners rejected some of the concepts which the refugees found promising and vice versa. However, both groups saw potential in four of the concept ideas. Also, an important insight from workshop 3 is that the human factor is important in archiving - both for the archivist and the museum professional, as well as the "archived". This would argue for creating co-archiving practices that do not stand on their own but rather are activities that both archivists, museum professionals and refugees could collaborate on together.
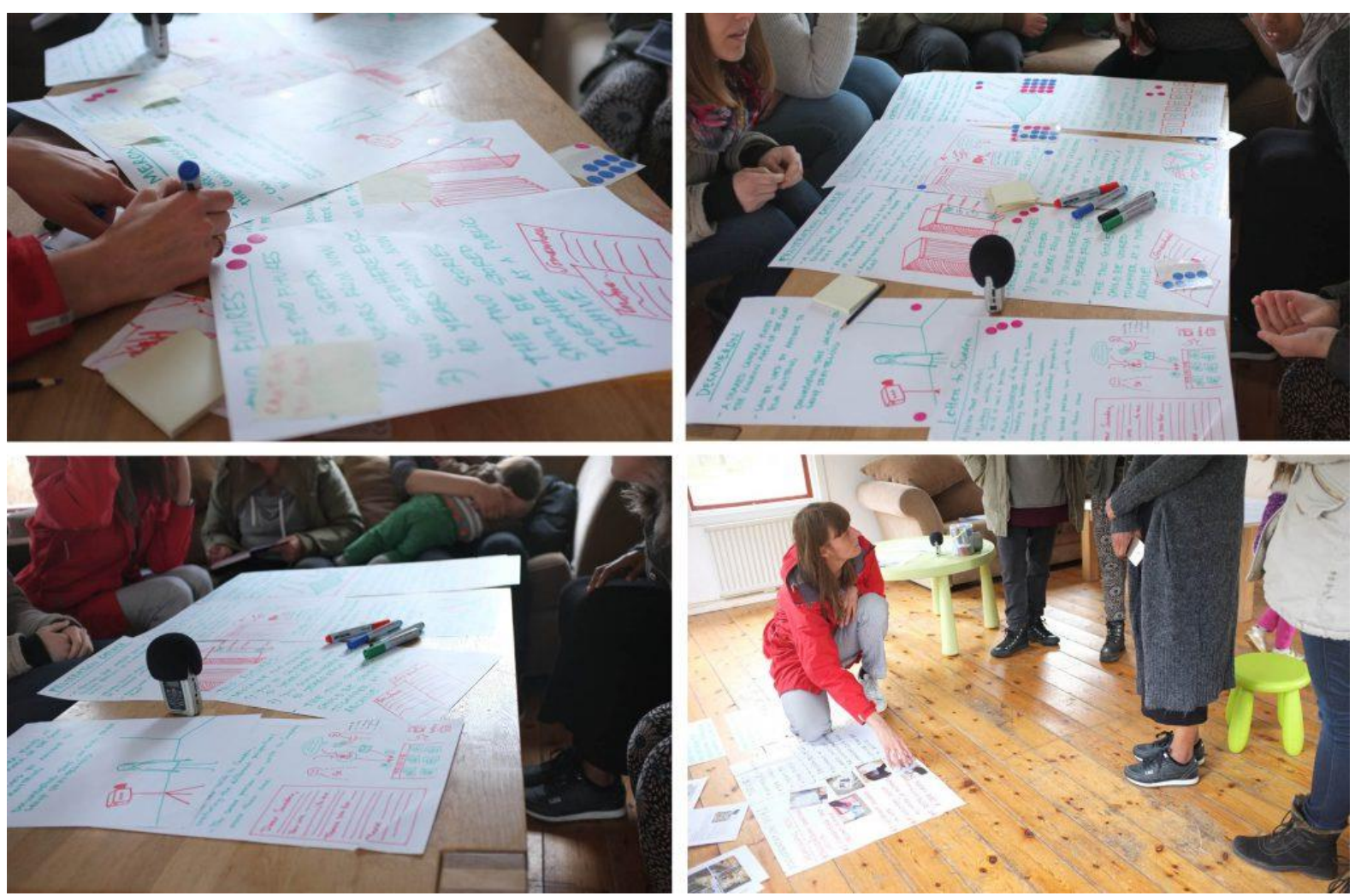

Figure 3 Concept ideas evaluated by the refugees at the third workshop at the refugee housing.

An overview of the workshop activities and results is presented in Figure 4. These insights served as a basis for the next step of the design process, which was to build a prototype to be evaluated and tested in workshop 4.

\section{WORKSHOP 1}

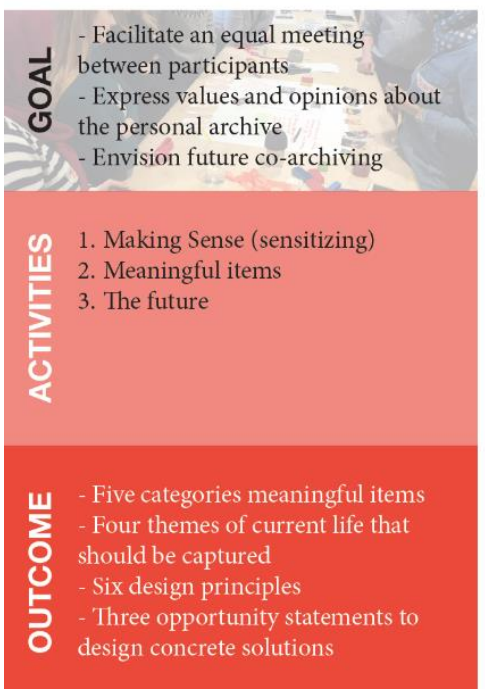

WORKSHOP 2

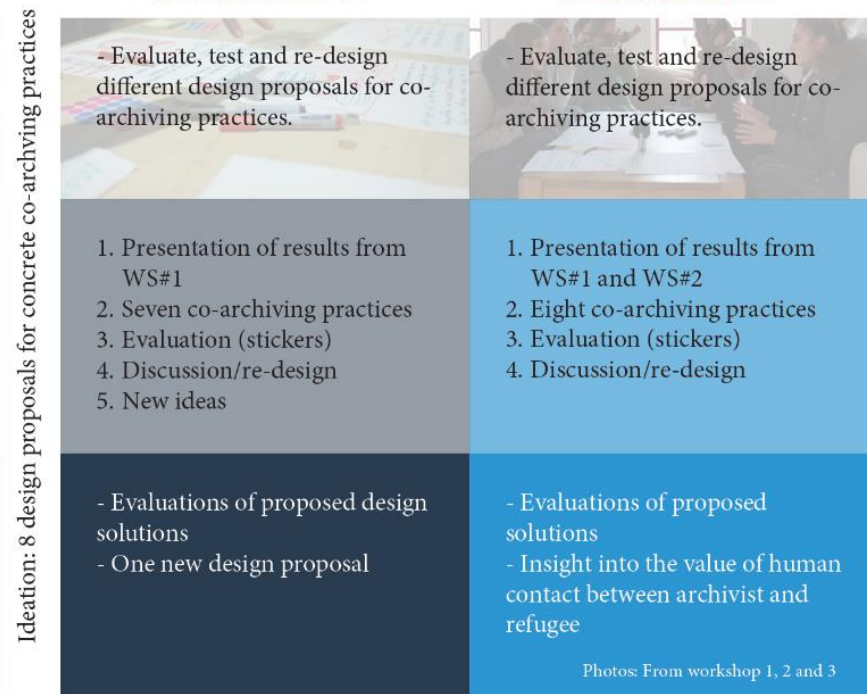

Figure 4 Overview of workshops 1-3: The design activities and their results and insights. 


\subsubsection{Workshop 4}

Building on the learning outcome of the three workshops, a cardboard prototype of a co-archiving toolbox (described in the following chapter) on a 1:1 scale was produced as well as materials for the co-archiving practices that the toolbox would contain. Eight museum professionals participated in the workshop.

The participants were asked to describe the process of using the toolbox in the field, following a series of steps from preparing the toolbox, introducing the toolbox, collecting the material, to concluding the archiving session (see Figure 6 below). The participants were also asked to develop a draft of a handbook about how to implement and use the toolbox.

\section{The prototype: Co-archiving Toolbox}

Based the workshop results, a physical co-archiving toolbox was developed and prototyped which contained a collection of co-archiving practices.

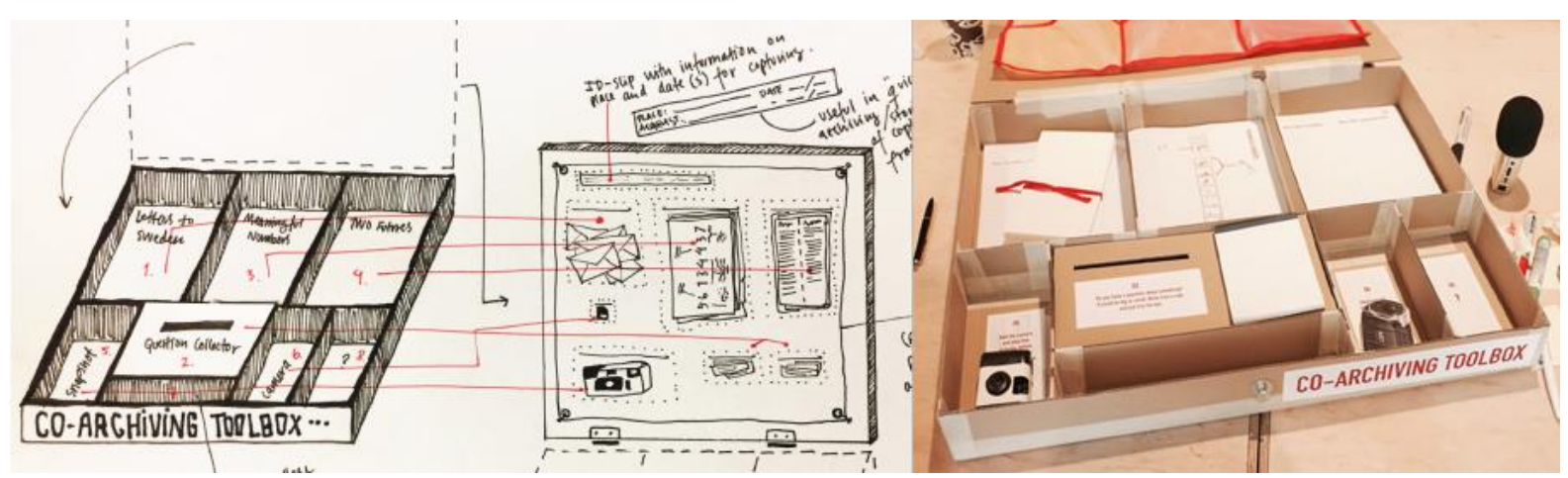

Figure 5 Sketches and cardboard prototype of the co-archiving toolbox.

The toolbox was created for archivists and museum professionals to use when collecting material in the field, in this case, a temporary refugee housing. The toolbox should be portable and "leavable", with built-in instructions. It should have a removable inset for collecting and organizing the content. The toolbox is meant to be administered by a public institution (a museum or an archive) and be placed at a temporary refugee housing for a period of two weeks. The people living there are to use the co-archiving practices included in the toolbox to document their life situations, hopes, dreams, fears, happiness levels and frustrations with little interference from the institution. When the period is over, the toolbox and all the material generated is to be picked up by the museum or archive and curated by an archivist who will then add it to their collections.

The toolbox currently includes seven co-archiving practices (introduced in the following chapter). The practices are designed to be open-ended, which means the refugees have a large degree of freedom to decide how they want to use them thus enabling them to participate in defining how their own stories and everyday lives are captured, recorded and archived. Some of the practices are for independent use, while others need facilitation and encourage social engagement. Some are more structured, while others are very open-ended. The practices generate archival material of different media formats: text, video, still images and audio.

The museum professionals who participated in workshop 4 developed a first draft of a timeline of how the toolbox should be deployed in the field. The co-archiving toolbox should come with a handbook for the archivists and museum professionals to use when planning and facilitating the coarchiving process which involves preparing, executing and concluding the work. 


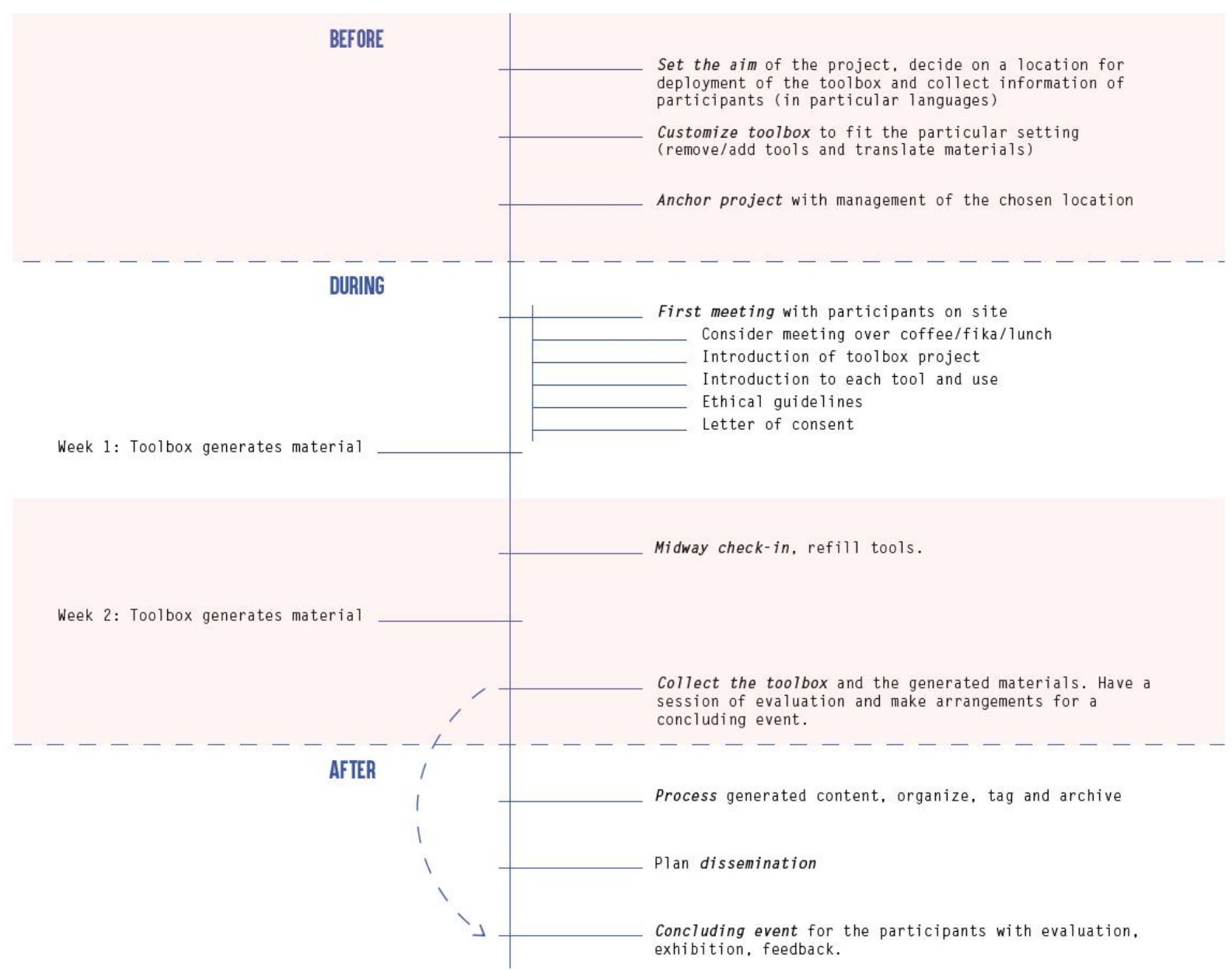

Figure 6 A timeline for how to use the co-archiving toolbox in the field.

\subsection{Seven co-archiving practices}

\section{Letters to Sweden}

The Letters to Sweden practice collects letters written to Sweden as if Sweden was a person. This may also involve audio recordings of the person reading the letter/talking to Sweden. The instructions given to the author are simply to "Write a letter to Sweden and put it in an envelope". The authors may (optionally) mark the letter with an ID number to match with other documents and archival material generated about that individual, which will then be stored in public archives (such as documents from the Swedish Migration Agency).

\section{Question Collector}

The Question Collector collects written questions from the refugees. The questions are open and may range from trivial, smaller, everyday questions to bigger, more meaningful questions about life and the future. The aim is not to answer the questions (and this ought to be carefully communicated) but rather to generate an alternative story about the life situation of the individuals. The instructions given were, "Do you have a question about something? It could be big or small. Write it on a note and put it in the box".

\section{Meaningful Numbers}

This practice encourages the refugees to "hijack" their dossier number (ID number at the Swedish Migration Agency) and use it to build a narrative about themselves. There are no rules - the individuals may associate their lives to the numbers in any way they find meaningful (e.g. special dates, street numbers, sizes). The narrative could be attached to the official documents about the individual being archived as a strategy to show that a human being exists behind the numbers. 
Instructions given: "Tell your story with your ID number. Write your number on the paper and write notes about what the numbers mean to you."

\section{Two Futures}

In this practice, the author is asked to describe two possible futures: 1) "Me in Sweden year 2027" and 2) "Me somewhere else in year 2027". The two versions of the future scenarios should be attached to each other. The authors may (optionally) mark the letter with an ID number to match with other documents and archival material. Instructions given: "What do you see in your future? Describe what your future would look like in 10 years if you stayed in Sweden and if you had not."

\section{Snapshots}

The participants are asked to take a series of photos of everyday life. A disposable camera is provided to take the pictures, which should then be passed on to the next person. Instructions printed on the camera: "Take five pictures of: 1) You, 2) a friend, 3) a meal, 4) a quiet place, 5) a noisy place, and pass it on to someone else."

\section{Moving Images}

The participants are asked to self-organize documentation sessions and record them with a video camera. A film director among the participants in the group is to be recruited and made responsible for the camera as well as for filming. A list of instructions is given to the filmmakers that suggests topics for film scripts such as 'share a story', 'sing a song', 'film everyday life' and 'have a group discussion'. Only those who have signed the letter of consent form ought to be filmed. Instructions given: "Shoot a movie about your life where you currently live. You decide what the film should be about."

\section{Audio Memory}

A phone number is provided that the participants can call and record an audio message about anything that they wish to share. The receiver of the message and how it will be used and stored ought to be carefully communicated. Instructions given: "Do you have something you wish to share? Call this number and leave a message."

\subsection{Testing the toolbox in the field}

We are currently planning the testing of the toolbox in the field. This will be carried out in collaboration with the project members of the Refugee Documentation Project. The test plan is currently in development; in addition to testing the co-archiving practices, it will also include activities that generate content to the handbook that will accompany the toolbox.

Based on the insights from test sessions and from engaging with the users, the toolbox will be iterated and re-designed. The final goal of this project is to produce a completely open source coarchiving toolbox where the physical box (files for replicating the build), with all its materials and the handbook, are made available to digitally download and re-produce.

\section{Concluding words}

An important insight gained at the workshops is that the generative tools introduced to the participants indeed provided a form of connection between them (Callon \& Latour, 1981). When preparing for the workshops, we put much effort into selecting a relevant set of tools aimed at creating conditions for the two groups of participants to meet on equal terms. One example is the sensitizing activity introduced during the week leading up the first workshop. The material generated from that activity was used at the workshop to set up productive communication between the participants and level the field between the two groups, and everyone brought something to the table, so to speak. When describing their individual contributions, the participants were also given space to introduce themselves and compare the variety of material generated. Although some of the participants found the exercise too open-ended and perhaps not concrete 
enough, it gave them the opportunity to connect and relate to each other through the shared experience of being part of the documentation exercise.

As part of this project, we also aimed at exploring how design research and co-design approaches could cross over into other domains and become part of developing practices in these fields. Through collaborative design work between the museum professionals and the refugees, we reconfigured archiving approaches and explored alternatives through design interventions and prototyping. One important learning experience gained from our collaboration with professionals who spend their days building archives thought to be representative collections is to acknowledge their work and not appear as though co-design brings in an approach that does not already exist. Our project is not meant to point out what the museum professionals do or do not do, but rather it is about creating conditions for people who come from different communities of practice to learn from each other via different ways of working, and as a result, come up with alternative and hopefully improved solutions to societal challenges. This is why the collaboration with the Refugee Documentation Project was established in the first place, but it ought to be better communicated to avoid misunderstandings. In our case, this mistrust was removed, and the discussion that ensued became greatly valuable, as the museum professionals were able to voice many concerns and thus share valuable insights into their practice and work.

As argued (Dunbar, 2001; Warren, 2016), contemporary archivists and museum professionals ought to assume a more inclusive approach to ensure increased diversity in public archives. This project is ultimately about transforming the cultural practices of archiving, and potentially, the writing of the history of our times as the result of an increase in the diversity of public archives. Given that we are still in the process of testing the co-archiving toolbox in the field, the potential of the toolbox to encourage archivists and museum professionals to assume a co-archiving approach and work in a more inclusive way is too early to evaluate. It is also too soon to determine whether the co-archiving toolbox will afford the possibility to capture alternative refugee stories and experiences, as we have yet not captured enough material to conduct a proper analysis. Based on the reactions from the workshop participants, the toolbox itself as a methodological approach that creates conditions for diversity is promising but will prove itself once put into practice. However, what is certain is that the prototype can be used as a practical example of what a co-archiving approach might entail as well as a contribution to the discussion about re-thinking the "archival mission". It also holds the potential to contribute to the discussion of how new practices for museological ethnology can be designed (Nikolíc, 2016) and how crisis situations may be documented by using methods characterized by an inclusive approach thus creating conditions for diversity.

Acknowledgements: We would like to thank everyone who contributed to this project: the workshop participants, the Refugee Documentation Project run by The Regional Museum in Kristianstad, Malmö Museums, Kulturen Museum and the Department of Cultural Sciences at Lund University, Interaction Design Master's students at K3 at Malmö University, and our colleagues in the Living Archives project. This work was funded by the Swedish Research Council.

\section{References}

Argyris, Chris, Putnam, Robert, and McLain Smith, Diana (1985). Action Science - Concepts, methods, and skills for research and intervention. San Francisco, CA: Jossey-Bass.

Callon, Michel, and Latour, Bruno (1981). Unscrewing the big Leviathan: How actors macro-structure reality and how sociologists help them to do so, in K. Knorr-Cetina \& A. V. Cicourel (Eds), Advances in social theory and methodology. Boston, London and Henley: Routledge \& Kegan Paul.

Derrida, Jacques (1995). Archive Fever: A Freudian Impression. Chicago and London: University of Chicago Press.

Dimitriova, Raya (2017). Designing a collaborative self-archiving system for vulnerable groups via co-design means. (Degree project/Master's thesis, Malmö University, Malmö) 
Dunbar, Anthony W. (2006). Introducing critical race theory to archival discourse: Getting the conversation started. Archival Science, 6(1), 109-129.

Lawson, Bryan. (2005). How Designers Think. Burlington, Mass.: Architectural press

Light, Ann, and Akama, Yoko (2014). Structuring Future Social Relations: The Politics of Care in Participatory Practice. Conference Proceeding PDC 2014, Windhoek, Namibia.

Living Archives (2017). IxD Master Student Project: Co-archiving Practices for Refugee Documentation. Retrieved 2018 March 6 from http://livingarchives.mah.se/2017/06/ixd-master-student-project-coarchiving-practices-for-flight-documentation/Manoff, Marlene (2004). Theories of the Archive from Across the Disciplines. Libraries and the Academy, 4, 9-25.

Nikolić, Dragan (2016). Lecture: Flight Documentation project presentation, The Department of Arts and Cultural Sciences, Lund University.

Nilsson, Elisabet M. (2015). The Smell of Urban Data: Urban Archiving Practices Beyond Open Data [Online]. Retrieved 2017 October 24 from https://medium.com/the-politics-practices-and-poetics-of-openness/thesmell-of-urban-data-476a460b0a59\#.brvhq01aj (Retrieved 2017-10-23)

Nilsson, Elisabet M. (2016). Prototyping collaborative (co)-archiving practices - From archival appraisal to coarchival facilitation. Conference proceedings 22nd International Conference on Virtual Systems \& Multimedia, Kuala Lumpur.

Nilsson, Elisabet M., and Barton, Jody (2016). Co-designing newcomers archives: discussing ethical challenges when establishing collaboration with vulnerable user groups. Conference proceedings Cumulus Hong Kong 2016: Open Design for E-very-thing - exploring new design purposes, Hong Kong.

Nilsson, Elisabet M., and Hansen Ottsen, Sofie Marie (2017). Becoming a co-archivist. ReDoing archival practices for democratising the access to and participation in archives. Conference proceedings Cumulus Kolding 2017, Kolding, Denmark, May 30-June 2.

Sanders, Elizabeth. B.N., and Pieter Jan Stappers (2012). The Convivial Toolbox : Generative Research for the Front End of Design. Amsterdam: BIS Publishers

Schön, Donald A. (1987). Educating the reflective practitioner. San Francisco, CA: Jossey-Bass.

Simonsen, Jesper, and Robertson, Toni (2013). The Routledge Handbook of Participatory Design. New York, NY: Routledge.

Swedish Migration Agency (2015). Applications for asylum received, 2015. The Migration Agency. Retrieved 2017 October 25 from http://www.migrationsverket.se

The Swedish Research Council (n.d). Codex rules and guidelines for research in Humanities and Social sciences. Retrieved 2017 October 25 from http://www.codex.vr.se

Warren, Kellee E. (2016). We Need These Bodies, But Not Their Knowledge: Black Women in the Archival Science Professions and Their Connection to the Archives of Enslaved Black Women in the French Antilles. Library Trends, 64(4), 776-794.

About the Authors:

Elisabet M. Nilsson, PhD in Education Sciences, Senior Lecturer in Interaction Design at Malmö University. Her research deals with the relationship between social change and technological development, exploring tools and methods for prototyping alternative futures and promoting dialogue, collaboration and knowledge transfer.

Sofie Marie Ottsen Hansen, MSc in Digital Design and Communication and a BA in journalism, adjunct and research assistant in Interaction Design at Malmö University. Her main research interests lie in the converging fields of design, technology and journalism. 